\title{
DIFICULDADES ENCONTRADAS NAS CAMPANHAS DE VACINAÇÃO DA TRÍPLICE VIRAL: REVISÃO INTEGRATIVA DA LITERATURA
}

\section{ARTIGO DE REVISÃO}

COELHO, Dayanna Mendes ${ }^{1}$

SOUZA, Sallery Dilce Ferreira de ${ }^{2}$

RODRIGUES, Marlon Bruno Santos ${ }^{3}$

MOREIRA, Roberto dos Santos ${ }^{4}$

BARROSO, José Augusto Macena ${ }^{5}$

SOARES, Fabiane Veloso ${ }^{6}$

COELHO, Dayanna Mendes. Et al. Dificuldades encontradas nas campanhas de vacinação da tríplice viral: Revisão integrativa da literatura. Revista Científica Multidisciplinar Núcleo do Conhecimento. Ano 05, Ed. 11, Vol. 24, pp. 92-106. Novembro de 2020. ISSN: 2448-0959, Link de acesso: https://www.nucleodoconhecimento.com.br/saude/campanhas-de-vacinacao

\footnotetext{
${ }^{1}$ Graduação Bacharelado em Enfermagem.

2 Bacharelado em Enfermagem.

${ }^{3}$ Bacharelado em Enfermagem.

${ }^{4}$ Bacharelado em Enfermagem.

${ }^{5}$ Bacharelado em Enfermagem.

6 Orientadora. Doutorado em Biotecnologia. Mestrado em Ciências da Saúde. Especialização em pós Graduação em Saúde Pública. Graduação em Enfermagem.
} 


\section{RESUMO}

Manter altas e homogêneas as coberturas vacinais na população brasileira é a única forma de evitar a transmissão da doença. Contudo, no Brasil nos últimos anos não foi possível ser efetivo quando a cobertura de vacinação do tríplice viral. Nesse contexto, o estudo tem como objetivo identificar as dificuldades encontradas nas campanhas de vacinação da Tríplice Viral. A metodologia aplicada nesse estudo é a revisão de literatura, no qual, foram selecionados 11 artigos para fundamentação. Após a análise dos artigos, organizou-se em 3 temas: as dificuldades encontradas nas campanhas de vacinação do tríplice viral, as deficiências nas campanhas de vacinação da Tríplice Viral e, as ações e estratégias da equipe de enfermagem e saúde para que campanhas de vacinação no Brasil tenham êxito. Concluindo-se, que de acordo com os estudos, as dificuldades nas campanhas de vacinação do tríplice viral são devido à falta de responsabilidade dos responsáveis das crianças, falta de informação sobre a importância da vacina tríplice viral, medo e receio dos efeitos colaterais da doença, e situação sociodemográfica dos indivíduos em todo o contexto dos municípios Brasileiros. Logo, é necessária uma base multiprofissional, que envolvam os indivíduos ativos das campanhas de saúde, e também, propor novas formas de campanhas, tais como as visitas domiciliares a partir das Unidades Básicas de Saúde, a fim, de diminuir a falta de acessibilidade à vacina.

Palavras-chave: Campanhas, tríplice viral, vacinação, sarampo.

\section{INTRODUÇÃO}

As vacinas são produtos indispensáveis para a prevenção de doenças e representam uma das maiores conquistas das ciências da saúde. Desempenham papel importante para controlar ou mesmo erradicar doenças imunopreviníveis, reduzindo, assim, sua morbimortalidade (DIAS; ALMEIDA, 2017).

O Programa Nacional de Imunizações (PNI) brasileiro possui uma trajetória admirável no desenvolvimento nacional sob âmbito das inovações tecnológicas e, particularmente, por ter logrado alcançar e sustentar altos níveis de cobertura as 
populações regionais do país, gerando um controle efetivo de várias doenças imunopreveníveis com a simultânea redução das desigualdades sociais.

Internacionalmente, o Brasil tem sido considerado um exemplo, dado o seu sucesso no alcance dos Objetivos de Desenvolvimento do Milênio, , em especial no que tange à redução da mortalidade infantil sobre crianças menores de cinco anos de idade, sendo o PNI parte das várias estratégias que contribuíram para colocar o país nessa posição (VICTORA, 2013).

Por ano, são mais de 300 milhões de doses de vacinas aplicadas na população brasileira. Para o ano de 2020, o orçamento previsto para a compra e distribuição de vacinas e insumos em todo o país, como kits de diagnósticos, é de $\mathrm{R} \$ 4,9$ bilhões. Ainda nesse ano, o Ministério da Saúde já investiu, até o mês de Setembro, cerca de $\mathrm{R} \$ 3,8$ bilhões na compra de vacinas e insumos, além dos investimentos já alocados na Biomanguinhos/Fiocruz um dos fornecedores nacionais (BRASIL, 2019).

Erradicar doenças em um país como o Brasil é um grande desafio, visto a dimensão continental que possui e as deficiências dos meios de acesso a vilarejos e vicinais nos interiores dos Estados. E a efetividade dos programas de imunização depende de um monitoramento da cobertura vacinal, equidade no acesso dos usuários às vacinas, segurança na qualidade e administração das vacinas, além de estar condicionada as suas diretrizes, metas e, ainda, as características da população (SATO, 2018).

A vacina tríplice viral (SCR) confere proteção contra sarampo, caxumba e rubéola, ao passo que o seu esquema básico indicado é de duas doses, onde a primeira é aplicada aos 12 meses de idade e a segunda aos quatro anos (NUNES et al., 2018).

Em 2016, o Brasil recebeu o Certificado de Eliminação do Sarampo, emitido pela Organização Pan Americana de Saúde, mas o perdeu em fevereiro de 2019, após 12 meses de movimentação do vírus sarampo no território nacional. Assim, desde a sua perda, a recuperação deste certificado tem sido uma das missões do Vacinação Brasil, sendo fundamental manter altas e homogêneas coberturas vacinais na população, a fim de evitar a transmissão da doença (OPAS, 2019). 
Assim, este estudo tem como questão norteadora a seguinte interrogativa: o manejo de uma enfermidade imunoprevenível é basicamente alcançado com cobertura vacinal, portanto, quais os desafios encontrados nas campanhas de vacinação do tríplice viral no Brasil?

São vários os desafios encontrados nas campanhas de vacinação da Tríplice Viral no Brasil, sendo um assunto sempre polêmico. Já não bastasse as dúvidas frequentes sobre a eficácia das vacinas e o medo de reações adversas a vacina, ainda tem a precariedade do sistema de saúde, falta de profissionais aptos para atender as necessidades de uma comunidade, condições para a execução das campanhas, como: transporte, água, alimentação, etc, sem falar da identificação dos profissionais nas campanhas nas ruas o que gera desconfiança dos clientes.

Este estudo se torna relevante a partir do momento em que mostraremos as dificuldades enfrentadas nas campanhas de vacina, em especial na campanha do tríplice viral, pois é uma das doenças que tem assolado nosso país.

Assim, este estudo tem como objetivo identificar as dificuldades encontradas nas campanhas de vacinação da Tríplice Viral, bem como descrever as problemáticas encontradas nos estudos em relação a campanha de vacinação da Tríplice Viral; apresentar as deficiências nas campanhas de vacinação da Tríplice Viral e identificar as estratégias de promoção da vacinação utilizadas durante as campanhas.

\section{METODOLOGIA}

\section{TIPO DE PESQUISA}

Trata-se de uma pesquisa descritiva-exploratória, na modalidade revisão integrativa. A Revisão Integrativa é considerada uma metodologia bastante relevante no âmbito da saúde, uma vez que possibilita a busca, a avaliação crítica e a síntese de evidências sobre o tema investigado, facilitando a identificação de resultados proeminentes e lacunas que acabam propiciando o desenvolvimento de futuras 
pesquisas, de modo a auxiliar o profissional na escolha condutas e tomadas de decisões, proporcionando-o, assim, um saber crítico (WHITTEMORE et al., 2014).

\section{BUSCAS NA LITERATURA - AMOSTRAGEM}

A coleta das informações para a pesquisa bibliográfica foi por meio da exploração da base de dados da Biblioteca Virtual em Saúde (BVS), acessada por meio da Arca Fiocruz; Biblioteca Científica Eletrônica Virtual (SCIELO); Literatura Latino Americana e do Caribe em Ciências da Saúde (LILACS); e periódicos de universidades e revistas da área de enfermagem.

Foram pesquisados os artigos publicados em língua portuguesa entre os anos de 2015 e 2020. Foram excluídos da amostra os artigos publicados em línguas estrangeiras, os que não apresentarem o texto na íntegra, monografias, dissertações, teses, artigos repetidos e os que não forem escritos por enfermeiros.

A busca na base de dados foi orientada pelas palavras-chave: "Vacina", "Tríplice Viral", "Sarampo", e foi realizada em todos os índices, visando captar o maior número de artigos publicados dentro do período proposto, segundo a temática em discussão.

\section{INSTRUMENTOS DE COLETA DE DADOS}

Para essa etapa do projeto foi elaborado um instrumento para consolidação dos dados no programa Microsoft Excel 2013, em formato de planilha, para organizar de maneira adequada as informações extraídas dos estudos selecionados, a fim de facilitar a análise das mesmas.

O instrumento possui o número de ordem, o ano de publicação do artigo, o título do artigo, os autores, a base de dados, o enfoque de pesquisa, os objetivos propostos, os métodos utilizados, os resultados encontrados e o nível de evidência científica.

Assim, esta etapa é muito importante, visto que ela será responsável por determinar a confiança dos resultados e fortalecer as conclusões sobre o estudo do tema investigado. (MENDES, et. al., 2008). 


\section{AVALIAÇÃO DOS ESTUDOS INCLUÍDOS NA REVISÃO INTEGRATIVA}

Após a leitura dos artigos selecionadas na íntegra, foi realizada a organização dos mesmos pelas temáticas propostas nesse projeto.

\section{QUESTÕES ÉTICAS}

Não houve necessidade de submissão ao Comitê de Ética Humano por não serem realizadas coletas de dados em seres humanos, conforme resolução ㄲo 466/12.

\section{RESULTADOS}

Foram encontrados 11 artigos que compuseram a amostra final. No quadro a seguir encontram-se os autores, ano de publicação, base de dados e resultados.

Quadro - Síntese dos artigos selecionados para revisão integrativa.

\begin{tabular}{|c|c|c|c|}
\hline & $\begin{array}{l}\text { AUTORES } \\
\text { (ANO) }\end{array}$ & $\begin{array}{l}\text { BASE DE } \\
\text { DADOS }\end{array}$ & RESULTADOS \\
\hline 01 & $\begin{array}{lll}\text { SILVA et al. } & \text { (2019) } & \end{array}$ & BVS & $\begin{array}{l}\text { Dos vinte municípios analisados, } 20 \% \quad(n=4) \\
\text { apresentaram a classificação de risco muito alto, } \\
55 \% \quad(n=11) \text { tiveram risco alto, } 15 \% \quad(n=3) \\
\text { apresentaram risco médio e } 10 \% \quad(n=2) \\
\text { classificaram-se com risco muito baixo. As } \\
\text { vacinas tetra viral, rotavírus e meningocócica C } \\
\text { apresentaram os menores valores de cobertura } \\
\text { na região: } 25 \%(n=5) \text { dos municípios alcançaram } \\
\text { a meta da homogeneidade da cobertura vacinal } \\
\text { entre vacinas e } 20 \% \text { ( } n=4) \text { dos municípios estão } \\
\text { com esse indicador zerado. As vacinas rotavírus, } \\
\text { pentavalente e poliomielite apresentaram as } \\
\text { maiores taxas de abandono. }\end{array}$ \\
\hline
\end{tabular}


02 NUNES et al. Scielo (2018)

03 FANTINATO et Scielo al. (2018)

04 (2018)
Houve baixa cobertura vacinal para o segundo reforço de DTP (72,3\%; IC95\%: 66-78) e segunda dose de SCR (76,7\%; IC95\%: 71-83). Os fatores relacionados à não vacinação foram significativos quando os cuidadores das crianças não eram os pais; famílias com três filhos ou mais; ser a partir do quarto filho; e não receber visita domiciliar de profissionais de saúde.

As taxas de anafilaxia foram 2,46 e 5,05 por doses distribuídas e aplicadas, respectivamente. Dentre os casos de anafilaxia, oito $(53,4 \%)$ eram do sexo masculino, e dentre os controles, 36 $(60 \%)$, com $\mathrm{p}=0,64$. $\mathrm{Na}$ análise bivariada referente à anafilaxia e alergia à proteína do leite de vaca (APLV), verificou-se OR $=51,62$, com $p$ $=0,00002$ e IC95\%: 5,59-476,11. As variáveis alergia alimentar familiar, aleitamento materno, evento adverso pós-vacinação (EAPV) anterior e vacinação simultânea não foram estatisticamente significativas $(p=0,48 ; p=1,00 ; p=0,49 ; p=$ 0,61). Taxas de anafilaxia por doses distribuídas/aplicadas ficaram acima de 1/100 mil doses aplicadas (taxa esperada). Anafilaxia e APLV apresentaram associação estatisticamente significativa. Não foram encontradas associações estatísticas referentes à vacinação simultânea, aleitamento materno, alergia alimentar familiar e EAPV anterior.

O perfil dos participantes aponta a maioria $(77,8 \%)$ do sexo feminino e homogeneidade etária nas faixas entre 25 a 30 anos, 35 a 40 anos 


\begin{tabular}{|c|c|c|c|}
\hline & & & $\begin{array}{l}\text { e } 40 \text { a } 45 \text { anos, com } 22,2 \% \text { respectivamente e } \\
\text { tempo de atuação no setor a mais de } 10 \text { anos } \\
\text { ( } 44,4 \%) \text {. Reconhecido que a maioria ( } 83,3 \% \text { se } \\
\text { considera capacitada para a atuação exigida no } \\
\text { referido setor, porém estes sinalizaram para a } \\
\text { importância da educação permanente para a } \\
\text { execução das funções desempenhadas. Os } \\
\text { participantes relataram vivenciar muitos entraves } \\
\text { para o adequado desempenho de suas funções } \\
\text { e, quanto ao SPNI-WEB, afirmaram que o } \\
\text { consideram um bom programa, porém com } \\
\text { certas limitações. }\end{array}$ \\
\hline 05 & $\begin{array}{l}\text { DIA; ALMEIDA } \\
(2017)\end{array}$ & Scielo & 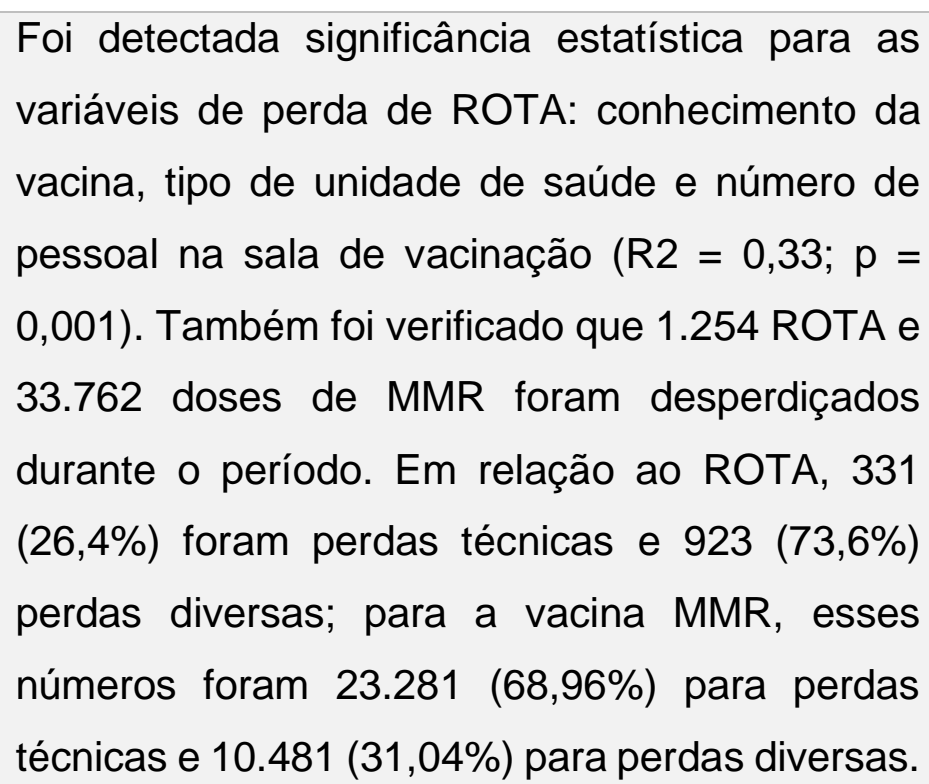 \\
\hline 06 & $\begin{array}{l}\text { AGUIAR et al. } \\
(2016)\end{array}$ & Lilacs & $\begin{array}{l}\text { Alcançamos um número considerável de pessoas } \\
\text { para vacinação aos finais de semana, atingindo, } \\
\text { desta forma, a meta preconizada pelo Ministério } \\
\text { da Saúde bem como, vencer a resistência } \\
\text { através da conscientização daqueles que se } \\
\text { recusaram realizar a vacinação. Para que isso } \\
\text { fosse possível informamos todos através de: } \\
\text { Panfletos o dia de visita do agente comunitário de }\end{array}$ \\
\hline
\end{tabular}




\begin{tabular}{|c|c|c|c|}
\hline & & & $\begin{array}{l}\text { saúde (ACS); Planejamento de propagandas via } \\
\text { carro de som; Campanha de vacinação na área } \\
\text { aos domingos; Nas recusas, pedir para assinar o } \\
\text { termo de recusa e se menores de idade } \\
\text { comunicar ao Conselho Tutelar; Realizar } \\
\text { educação em saúde na Unidade de Saúde } \\
\text { Básica periodicamente; Realizar busca ativa nas } \\
\text { escolas, para identificação dos não vacinados. }\end{array}$ \\
\hline 07 & ROSA (2016) & Univates & $\begin{array}{l}\text { O principal fator de não adesão ao calendário } \\
\text { vacinal foi em relação à presença de doença no } \\
\text { período correto de vacinação e o esquecimento. } \\
\text { Apesar dos responsáveis terem } \\
\text { conmaihecimento sobre a importância da } \\
\text { vacinação para evitar doenças, não reconhecem } \\
\text { a necessidade de realizar a aplicação da vacina } \\
\text { na idade e intervalo corretos e apresentam } \\
\text { percepção errônea acerca das contraindicações. }\end{array}$ \\
\hline 08 & $\begin{array}{l}\text { ARAUJO; } \\
\text { SOUZA; } \\
\text { PINHO (2019) }\end{array}$ & FioCruz & $\begin{array}{l}\text { Apenas } 38,5 \% \text { dos trabalhadores relataram } \\
\text { situação vacinal completa para todas as vacinas } \\
\text { do calendário do adulto. Mostraram-se } \\
\text { positivamente associados à completude do } \\
\text { cartão vacinal: sexo feminino (IC95\%: 1,42-2,10), } \\
\text { ser profissional de saúde de cuidado direto ao } \\
\text { paciente (IC95\%: 1,26-1,71), ter recursos } \\
\text { técnicos para o desenvolvimento das atividades } \\
\text { profissionais (IC95\%: 1,02-1,34), apoio social no } \\
\text { trabalho (IC95\%: 1,02-1,26), contato com } \\
\text { material biológico (IC95\%: 1,39-1,75), preparo de } \\
\text { medicação (IC95\%: 1,10-1,44) e autopercepção } \\
\text { positiva da saúde (IC95\%: 1,03-1,41). }\end{array}$ \\
\hline
\end{tabular}


09 MORAES et al. Scielo (2018)

10 MACHADO et Master al. (2020) Editora

11 ALVARENGA Fiocruz et al. (2018)
Foram descritos os principais componentes das vacinas oferecidas pelo sistema público de saúde brasileiro e eventos adversos associados a esses elementos. Com exceção de reações inflamatórias locais e efeitos raros como exacerbação de doenças autoimunes e alergias, não foi demonstrada relação causal entre a administração de vacinas e autismo, mal de Alzheimer ou narcolepsia. Por outro lado, a falta de informações e a divulgação de informações não científicas têm contribuído para a reemergência de doenças infecciosas em diversos países no mundo e põe em risco planos globais para a erradicação de doenças infecciosas.

O número de casos de Sarampo, doença considerada eliminada no Brasil desde 2016, vem aumentando gradativamente desde 2018. Somados os casos confirmados e notificados dos anos de 2018 e 2019 obtém-se um total de 28.529 casos confirmados de uma doença que é de notificação compulsória no Brasil desde 1968. Observa-se que a cobertura vacinal da vacina tríplice viral, os dados do ano de 2017 mostram que apenas $85,2 \%$ da meta nacional de vacinação foi atingida.

No total 395 perigos foram identificados, sendo 278 nas etapas de expansão celular e 117 nas etapas de produção viral. Os perigos mais encontrados foram os biológicos $(53,4 \%)$, seguido pelos perigos físicos $(45,2 \%)$ e químicos 
(1,4\%). Na análise global 123 PCC foram mapeados.

Fonte: autor.

\section{DISCUSSÃO}

Com base nos artigos coletados identificou-se vários fatores que mostram as dificuldades nas campanhas de vacinação, como altas taxas de anafilaxias, medo da população de reações adversas, falta de informação sobre a vacina, as perdas das doses vacinais no período foram significantes, tanto em termos percentuais quanto relativamente a seus valores monetários, baixa procura da população, falta de profissionais aptos para atender a demanda de uma comunidade, condições precárias para a execução da campanha.

Nesse ensejo, serão pontuados 3 tópicos com base na revisão de literatura, sendo eles, as dificuldades encontradas nas campanhas de vacinação do tríplice viral, as deficiências nas campanhas de vacinação da Tríplice Viral e por fim, as ações e estratégias da equipe de enfermagem e saúde para que campanhas de vacinação no Brasil tenham êxito.

\section{DIFICULDADES ENCONTRADAS NAS CAMPANHAS DE VACINAÇÃO DO TRÍPLICE VIRAL}

As dificuldades encontradas nas campanhas de vacinação são decorrentes de todo o conjunto social dos pais e responsáveis de crianças, bem como o fortalecimento do movimento antivacina, o qual contribui para a queda das coberturas vacinais e favorece a reintrodução de doenças imuproveníveis já em eliminação (SILVA et al., 2019)

Quanto a percepção de Silva et al. (2019) as dificuldades do atendimento em muitas campanhas de vacinação referem-se a desigualdade geográfica e a distribuição dos 
imunobiológicos. Que em sua maioria, são atendidas em maior cobertura as zonas urbanas e em menor e/ou zero nas zonas rurais.

"Condições sociodemográficas, como renda familiar, baixa escolaridade dos responsáveis, número elevado de filhos por mãe e a ordem de nascimento das crianças", foram associadas a não vacinação, visto que o cuidador tende a estar centrado em atividades de geração de renda, a fim de assegurar a subsistência da sua família, não atendando-se as ações de prevenção ou de promoção da saúde, indo em busca dos serviços de saúde somente para o tratamento de problemas instalados (NUNES et al., 2018, p.15)

Outros fatores que influenciam na dificuldade encontrada nas campanhas de vacinação responsáveis pelo não comparecimento das crianças é em relação ao aparecimento de reações e eventos adversos em pacientes que aplicaram a Vacina tríplice viral. Uma vez que, alguns produtos utilizados na produção de vacina, tais como: sais minerais e de cálcio, derivados microbianos e emulsões de óleo em água, causam reações alérgicas e inflamatórias.

De acordo com Aps et. al. (2018), um fator encontrado como agravante ao não comparecimentos das crianças a programas de vacinação é decorrente das notícias vinculadas nas mídias sociais informais que sugeriram o autismo ou TEA (Transtorno do Espectro Autista) como uma das principais doenças conferidas à prática da vacinação, sobretudo, à vacina tríplice viral (sarampo-caxumba-rubéola).

Assim, como quaisquer outros produtos biológicos, as vacinas também podem causar efeitos indesejáveis, requerendo uma atenção especial, visto que "podem desencadear eventos adversos leves ou graves, esperados ou inusitados e que, se não forem identificados, investigados e acompanhados, levam a prejuízos na adesão ao programa de imunização" (FANTINATO, 2014/2015, p.2).

É o que ocorre a Vacina de tríplice viral, que de acordo com o estudo de Fantinato et al. (2018) gera anafilaxia, que é um dos eventos adversos mais graves associados a ela. 
Alvarenga et al. (2018) afirmam que ainda é necessário um maior conhecimento quanto aos riscos biológicos, químicos e físicos relacionados as etapas de fabricação da vacina de tríplice viral.

No estudo de Moura et. al. (2018), as dificuldades destacadas pelos responsáveis no que diz respeito a não vacinação da criança são distintos, sendo algumas destas relacionadas a falta de responsabilidade dos cuidadores das crianças com o compromisso da vacinação, por simples recusa, perda da caderneta de vacinação ou falta de tempo, como o afirmado pelos pais/responsáveis.

Outros motivos da não vacinação apontaram responsabilidade da gestão pública de saúde, entre eles a dificuldade de acesso dos usuários aos locais de vacinação, falhas relacionadas à gestão das salas de vacinação - como a falta de agendamento da vacina, este que é um determinante fundamental para a orientação dos pais/responsáveis, ausência de garantia do estoque do imunobiológico, falta de flexibilidade nos horários de funcionamento das unidades de saúde (MOURA et al., 2018).

No que tange a vacinação para o calendário do adulto, foram descritas prevalências conforme o Programa Nacional de Imunização (PNI) e a completude dos projetos vacinais "segundo variáveis sociodemográficas, econômicas, do trabalho, sobrecarga doméstica, psicossociais, satisfação e apoio social no trabalho, exposição ocupacional, hábitos de vida, situação de saúde e autopercepção da saúde". (ARAUJO et al., 2019, p.1).

\section{DEFICIÊNCIAS NAS CAMPANHAS DE VACINAÇÃO DA TRÍPLICE VIRAL}

Conforme ressalta Nunes et. al. (2018), o cumprimento de ações como o monitoramento da cobertura vacinal, a equidade no acesso dos usuários às vacinas $\mathrm{e}$ a segurança na qualidade e gestão das vacinas, estando essas condicionadas as suas diretrizes, metas e, ainda, às características da população, a fim de obter uma boa efetividade dos programas de imunização, é fundamental. 
No que tange ao atendimento, propriamente dito dos enfermeiros para com os pacientes, recebedores das vacinas, as dificuldades vivenciadas pelas equipes de enfermagem, Rocha (2018) sinalizou a sobrecarga de tarefas na sala de vacinação, a falta de insumos e materiais, a dificuldade de manuseio do SIPNI-WEB e a ausência de educação permanente para a equipe de enfermagem de forma contínua. Os profissionais apontaram que, para o alcance da cobertura vacinal relativo ao programa, a busca ativa dos faltosos, a educação continuada para os profissionais e maiores informações para a população são estratégias fundamentais.

De acordo com Rocha (2018), para a resolução das dificuldades vivenciadas pelas equipes de enfermagem atuantes em sala de vacinação, além de auxiliar na elaboração de estratégias para facilitação e melhoria da atuação no setor de forma a repercutir em melhores índices de cobertura vacinal.

Em seu estudo, Dias e Almeida (2017) destacam que maior parte das estatísticas versam sobre a falta de conhecimento da vacina, tipo de unidade de saúde e número de pessoal na sala de vacinação.

De acordo com Nunes et. al. (2018), a realização de atividades da atenção básica, a fim de estimular as estratégias do programa, ainda se faz necessária, uma vez que estas são fundamentais para a geração de um impacto coletivo nas ações de imunização quanto a prevenção das doenças imunopreveníveis, contribuindo para a diminuição da ocorrência de casos graves e de sequelas e garantindo a redução dos custos de internações/tratamentos; sendo também capaz de orientar a oferta de serviço, visto a necessidade da população, corrigir distorções e superar barreiras relacionadas ao acesso de serviços públicos de saúde e, sobretudo, melhorar a qualidade de vida das crianças dessa população.

Na perspectiva de Domingues et al. (2015), a eficácia e o risco de eventos adversos variam, em alguns casos, de acordo com a idade, o estado nutricional, a presença de infecções e outros fatores. Portanto, o comportamento de algumas vacinas poderá ser diferente a depender das características e condições de saúde de determinada população. Para se estimar segurança e eficácia da vacina no país onde é proposta 
sua introdução, deve ser realizada uma cuidadosa avaliação da adequação dos estudos conforme as peculiaridades daquela população. Cruz e Bizarria (2019), enfatizam que os desafios no âmbito da prevenção e tratamento do sarampo condiz mais a situação de medo e insegurança da população, do que pela falta de informação em si.

Nesse ensejo, Domingues et al. (2015) afirmam que mesmo em caráter preventivo, o Sistema de Saúde Pública, deve considerar o quadro de saúde da criança, que será fundamental para determinar o grau de eficácia e reação dos indivíduos.

\section{AÇÕES E ESTRATÉGIAS DA EQUIPE DE ENFERMAGEM E SAÚDE PARA ÊXITO NAS CAMPANHAS DE VACINAÇÃO NO BRASIL}

Considerando que a vacina tríplice viral é distribuída gratuitamente pelo Governo, o não atingimento desta meta estipulada torna-se é um problema de saúde pública que deve ser atenciosamente estudado para buscar soluções eficazes contra o Sarampo, para que seja evitado o ressurgimento desta doença altamente infeciosa que já é considerada como eliminada no Brasil (MACHADO et al., 2020)

Conforme Silva et al. (2019), há necessidade de estratégias de imunização e vigilância em municípios que apresentam campanhas de vacinação baixa, com a finalidade de evitar quadros epidemiológicos desfavoráveis. A dissociação da população a áreas que não comtemplem zonas com unidades básicas de saúde provoca um desequilíbrio nas ações de vacinação.

Os benefícios da vacinação sempre devem ser informados a população, cabendo aos profissionais o papel de divulgar informações verídicas e com respaldo científico sobre o assunto, cumprindo com o compromisso ético e profissional adjunto à sociedade (APS et al., 2018).

Dito isso, espera-se que as campanhas periódicas de vacinação, adjuntas à vacinação de rotina, sejam capazes de continuar garantindo a imunidade da população, de modo a minimizar os riscos de surto. O sucesso do seu desempenho será dependente do 
comprometimento de todos os envolvidos, cujo apoio tem-se mostrado indispensável para a eliminação do sarampo no Brasil e nas demais regiões das Américas (MOURA et al., 2018).

De acordo com Aguiar et. al. (2016), o profissional de enfermagem tem como responsabilidade, atribuir a população ações de educação e promoção em saúde, informando-os sempre sobre os inúmeros benefícios que a vacinação proporciona, de modo a se contrapor aos mitos relacionados a essa temática. Além de explanar que a vacina é a forma mais eficaz no combate às doenças imunopreveníveis, contribuindo, portanto, na diminuição da morbimortalidade das mais diversas afecções e, reduzindo por conseguinte, as barreiras que ainda persistem no processo de conscientização da população sobre a importância da prevenção de doenças através da vacinação, favorecendo a adesão durante as campanhas.

Ainda de acordo com Aguiar et. al. (2016), as campanhas devem ser realizadas não apenas durante surtos e campanhas pontuais, mas sim constantemente, conferindo ao enfermeiro a missão de iniciar o processo de sensibilização por meio da educação em saúde, já nas salas de vacinas, corroborando a importância da vacinação e das doenças que elas previnem e suas complicações.

Segundo Domingues et al. (2015), para a garantia da estabilidade de oferta de vacinas, a consolidação da saúde na área de imunobiológicos tem sido fundamental no que tange o calendário de vacinação, visto que têm sido instituídos calendários diferenciados de vacinação para crianças, adolescentes, adultos e idosos.

Para Rosa (2016), a enfermagem tem papel fundamental neste sentido pois tem a função de estar presente na sala de vacina e prestar todos os esclarecimentos necessários para o conhecimento dos pais e adesão no serviço pela ciência da importância do mesmo. Logo, através da educação continuada e permanente em saúde é viável a melhoria da atenção neste nível de cuidado.

Uma atuação mais eficiente e esclarecedora por parte dos profissionais de saúde, principalmente do vacinador, junto aos responsáveis, é de suma importância para 
diminuir o número de crianças com atraso. Para tanto, é necessário que este profissional seja capacitado continuamente, buscando formas alternativas de informar, esclarecer e conscientizar sobre a importância de realizar as vacinas de forma correta (ROSA, 2016).

De acordo com Sales et al. (2017), é necessário também, enfatizar pesquisas que comprovem a baixa reatogenicidade e a segurança das vacinas. Pois somente assim, podem incentivar a vacinação de indivíduos que a evitam por possuir apreensão de manifestar eventos adversos.

Portanto, estudos frequentes sobre as reações devem ser realizados para intensificar a confiança e divulgar os benefícios das vacinas, pois coberturas homogêneas são fundamentais para o controle das doenças e para alcançar, em alguns casos, a erradicação.

\section{CONSIDERAÇÕES FINAIS}

Portanto, nota-se que de acordo com os estudos abordados as dificuldades encontradas nas campanhas de vacinação do tríplice viral são inúmeras, destacandose a desde a falta de responsabilidade dos responsáveis das crianças, falta de informação sobre a importância da vacina tríplice viral, medo e receio dos efeitos colaterais da doença, e situação sociodemográfica dos indivíduos.

Contudo, as deficiências das campanhas de vacinação são muitas, sendo desde o acesso a informação até a falta de campanhas eficazes, que atinjam todo o contexto dos municípios Brasileiros.

Outro fator que é bastante enfático, é relacionado a situação dos testes de reação de efeito das vacinas de tríplices virais pelas indústrias farmacêuticas, que consideram apenas corpos saudáveis. Todavia, seria importante que o Sistema Único de Saúde compreendesse que o efeito das vacinas em um indivíduo com a saúde estável não é a mesma com a saúde em deficiência. O que gera conflito com efeito versus reação em cada pessoa. 
Portanto, para que as campanhas sejam eficazes, faz-se necessário um estudo com base multiprofissional, que envolvam todos os indivíduos ativos das campanhas de saúde, para que possa conciliar a necessidade da vacinação de tríplice viral com o acesso real da população a informação. E também, propor novas formas de campanhas, tais como as visitas domiciliares a partir das Unidades Básicas de Saúde, a fim, de diminuir a falta de acessibilidade à vacina.

\section{REFERÊNCIAS}

ALVARENGA, Celina Vieira da Cunha Guedes, et al. Mapeamento e Avaliação dos Perigos e Pontos Críticos de controle de produção do IFA de rubéola para a vacina de tríplice viral. Anais do VI seminário anual científico e tecnológico [recurso eletrônico] : 8-10 de maio de 2018 / Organização: Instituto de Tecnologia em Imunobiológicos. - Rio de Janeiro: Bio-Manguinhos, 2018.

APS, Luana Raposo de Melo Moraes et al. Eventos adversos de vacinas e as consequências da não vacinação: uma análise crítica. Revista de Saúde Pública, v. 52, p. 40, 5 abr. 2018. Disponível em: https://doi.org/10.11606/s15188787.2018052000384 Acesso em: 27 out. 2020

ARAÚJO, Tânia Maria de; SOUZA, Fernanda de Oliveira; PINHO, Paloma de Sousa. Vacinação e fatores associados entre trabalhadores da saúde. Cad. Saúde Pública (Online) ; 35(4): e00169618, 2019.

BRASIL. Ministério da Saúde. Secretário fala sobre orçamento, produção e fornecimento de vacinas no país e cenário internacional. Governo Federal do Brasil, 2019. Disponível em: <https://www.gov.br/saude/ptbr/assuntos/noticias/secretario-nacional-de-vigilancia-em-saude-fala-sobrefornecimento-e-orcamento-para-vacinas-alem-de-investimento-para-a-area>. Acesso em: 15 set 2020.

DIAS, Barbara F; ALMEIDA, Renan MVR. PERDA DE VACINA ANTI ROTAVÍRUS E VIRAL TRIPLA EM SALAS DE VACINAÇÃO: ESTUDO 
TRANSVERSAL. MedicalExpress (São Paulo, online) [online]. 2017, vol.4, n.4, M170405. ISSN 2358-0429. Disponível em: http://dx.doi.org/10.5935/medicalexpress.2017.04.05. Acesso em: 20 out. 2020

DOMINGUES C.M.A.S.; WOYCICKI, J.R.; REZENDE, K.S.; HENRIQUES, C.M.P. Programa nacional de imunização:: a política de introdução de novas vacinas. Rev. G\&S, 2015; 6(4):Pág. 3250-3274. Disponível em: https://periodicos.unb.br/index.php/rgs/article/view/3331. Acesso em: 25 out 2020.

FANTINATO, Francieli Fontana Sutile Tardetti et al. Anafilaxia relacionada à vacina sarampo, caxumba e rubéola, Santa Catarina, Brasil, 2014 e 2015. Cad. Saúde Pública [online]. 2018, vol.34, n.3, e00043617. Epub Mar 12, 2018. ISSN 16784464. Disponível em: https://doi.org/10.1590/0102-311x00043617 Acesso em: 27 out 2020.

GIL, Antonio Carlos. Como elaborar projetos de pesquisa. 12. ed. São Paulo: Atlas S.A, 2010.

MACHADO, Luís Felipe Barbosa; FERREIRA, Nathália Máyra Dos Santos; DAMASCENO, Camilla Ribeiro; SANTOS, Andreza Cristian Pereira Dos; PEREIRA, Caroline Dias; CESAR, Jorgino Júlio. Recusa vacinal e o impacto no ressurgimento de doenças erradicadas. Brazilian Journal of Surgery and Clinical Research BJSCR. Vol.32,n.1,pp.12-16 (Set - Nov 2020).

MENDES, Karina Dal Sasso; SILVEIRA, Renata Cristina de Campos Pereira; GALVAO, Cristina Maria. Revisão integrativa: método de pesquisa para a incorporação de evidências na saúde e na enfermagem. Texto contexto enferm., Florianópolis , v. 17, n. 4, p. 758-764, dez. 2008 . Disponível em: https://doi.org/10.1590/S0104-07072008000400018. Acesso em: 14 jun. 2020

MINISTÉRIO DA SAÚDE: Ministério da Saúde garante maior distribuição de vacina contra sarampo dos últimos dez anos. Distrito Federal, 20 set. 2019. Disponível em: https:// www.saude.gov.br/noticias/agencia-saude/45830-ministerio- 
da-saude-garante-maior-distribuicao-de-vacina-contra-sarampo-dos-ultimos-dezanos. Acesso em: 03 abr. 2020.

MOURA, Ana Débora Assis et al. Estratégias e resultados da vacinação no enfrentamento da epidemia de sarampo no estado do Ceará, 20132015. Epidemiol. Serv. Saúde [online]. 2018, vol.27, n.1, e201634310. Epub Feb 01, 2018. ISSN 2237-9622. Disponível em: http://dx.doi.org/10.5123/s167949742018000100010. Acesso em: 27 set 2020.

NUNES, Daniele Monteiro et al. Inquérito da cobertura vacinal de tríplice bacteriana e tríplice viral e fatores associados à não vacinação em Santa Maria, Distrito Federal, Brasil, 2012. Rev Pan-Amaz Saude [online]. 2018, vol.9, n.1, pp.917. ISSN 2176-6223. Disponível em: http://dx.doi.org/10.5123/s217662232018000100002. Acesso em: 27 mar. 2020

ROCHA, Robson Machado. Dificuldades enfrentadas pela equipe de enfermagem na sala de vacinação para o alcance de coberturas vacinais. Centro Universitário do Cerrado. Patrocínio, 2018.

ROSA, Marcos Alexandre Viana. Fatores que dificultam a adesão ao calendario vacinal em crianças até seis meses de idade. Centro Universitário Univates. Lajeado, 2016.

SALES, Magda Coeli Vitorino; ARAÚJO, Milena Carolina Braga de; ALMEIDA, Camila Aparecida Pinheiro Landim; MOURA, Luana Kelle Batista. Eventos adversos pósvacinação: revisão integrativa / Post-vaccination adverse events: integrative review. Rev. enferm. UFPE on line ; 11(supl.10): 4243-4253, out.2017.

SATO, Ana Paula Sayuri. Qual a importância da hesitação vacinal na queda da cobertura vacinal no Brasil ?. Revista de Saúde Pública , v. 52, p. 96, 22 nov. 2018. Disponível em: https://doi.org/10.11606/S1518-8787.2018052001199 Acesso em: 23 mar. 2020 
SILVA, Aline Beatriz dos Santos; ARAÚJO, Ana Catarina de Melo; SANTOS, Michelle Caroline da Silva; ANDRADE, Maria Sandra; MENDONÇA, Rafael Mota. Indicadores de cobertura vacinal para classificação de risco de doenças imunopreveníveis. Revista Brasileira de Promoção da Saúde, 2019; 32:9285. Disponível em: $<$ https://periodicos.unifor.br/RBPS/article/download/9285/pdf>. Acesso em: 25 out 2020.

STETLER, Cheryl B. et al. Utilization-focused integrative reviews in a nursing service. Appl Nurs Res. 1998;11(4):195-206. Disponível em: https://doi.org/10.1016/S0897-1897(98)80329-7 Acesso em: 14 jun. 2020.

VICTORA, Cesar G. 40 anos do Programa Nacional de Imunizações: o desafio da equidade. : o desafio da equidade. Epidemiologia e Serviços de Saúde, [s.I.], v. 22, n. 2, p. 201-202, jun. 2013. Instituto Evandro Chagas. Disponível em: http://dx.doi.org/10.5123/s1679-49742013000200001.00 Acesso em: 20 out 2020.

WHITTEMORE, Robin; KNAFL, Kathleen. The integrative review: update methodology. J Adv Nurs. 2005;52(5):546-53. Disponível em: https://doi.org/10.1111/j.1365-2648.2005.03621.x Acesso em: 14 jun. 2020.

Enviado: Novembro, 2020.

Aprovado: Novembro, 2020. 